\title{
MITO-LÓGICAS DEL DIABLO EN EL CHACO ARGENTINO
}

PABLO QUINTERO ${ }^{1}$

UFRGS

\begin{abstract}
RESUMEN: Desde el período de la presencia hispánica en América, la extensa región del Chaco, habitada históricamente por diversas etnias indígenas, ha sido representada como una geografía unida a los imaginarios coloniales y poscoloniales de herejía y de barbarie, desplegados por los sectores hegemónicos ligados en un primer momento a la administración eclesiástico-monárquica española, y posteriormente emparentados con el gobierno y la corporación militar de la Argentina decimonónica. Estos imaginarios estuvieron representados a través de diferentes encarnaciones mitológicas en torno a la figura del diablo que simbolizaban la supuesta malignidad del Chaco, y en torno a las cuales se configuraron narraciones mitológicas que proyectaban una lógica bicéfala de explicación/resolución para dicha negatividad. En el siglo XX los sectores subalternos indígenas del Chaco, produjeron a su vez una narración mitológica que resignificaba con otra direccionalidad las anteriores estampas demoníacas. Este artículo se interesa por describir y aproximarse analíticamente a las lógicas culturales que conllevaron a la configuración de estas distintas "mito-lógicas del diablo". El trabajo resalta el carácter necesariamente histórico de los mitos y la centralidad del poder como dimensión constitutiva de las narraciones mitológicas que se han gestado en el Chaco Argentino alrededor de los diferentes personajes demoníacos que aparecen a lo largo de los siglos como encarnaciones de una particular retórica de hegemonías y subalternidades.
\end{abstract}

PALABRAS CLAVE: diablo; mito; Historia; pueblos indígenas; Chaco Argentino.

RESUMO: Desde o período da presença hispânica na América, a extensa região do Chaco, habitada historicamente por diversas etnias indígenas, foi representada como uma geografia unida aos imaginários coloniais e poscoloniais de heresia e barbárie, desenvolvidos pelos setores hegemônicos ligados em um primeiro momento à administração eclesiásticomonárquica espanhola, e, no século XIX, vinculados com o governo e a corporação militar da Argentina. Estes imaginários estiveram representados através de diferentes encarnações mitológicas em torno da figura do diabo que simbolizavam a suposta malignidade do Chaco, e acerca das quais se configuraram narrações mitológicas que projetavam uma lógica bicéfala de explicação/resolução para dita negatividade. No século XX, os setores subalternos indígenas do Chaco, produziram, por sua vez, uma narração mitológica que ressignificava com outra direcionalidade as anteriores representações demoníacas. Este artigo tem por objetivo descrever e explorar analiticamente as lógicas culturais que implicam a configuração destas distintas "mito-lógicas do diabo". O trabalho ressalta o caráter necessariamente histórico dos mitos e a centralidade do poder como dimensão constitutiva das narrações mitológicas que se

\footnotetext{
1 Doctor en Antropología por la Universidad de Buenos Aires, Master en Ciencias Sociales por la Facultad Latinoamericana de Ciencias Sociales (sede Argentina), y Antropólogo por la Universidad Central de Venezuela. Investigador posdoctoral del Programa de Pós-Graduação em Antropologia Social y profesor del Departamento de Antropologia de la Universidade Federal do Rio Grande do Sul. E-mail: pablo.quintero@ufrgs.br.
} 
gestaram no Chaco Argentino em torno dos diferentes personagens demoníacos que aparecem ao longo dos séculos como encarnações de uma particular retórica de hegemonias $e$ subalternidades.

PALAVRAS-CHAVE: diabo; mito; História; povos indígenas; Chaco Argentino.

ABSTRACT: Since the Hispanic period in America, the broad region of Chaco, historically inhabited by many different indigenous ethnic groups, was represented as a geographically united to colonial and post-colonial imaginaries of heresy and barbarism, developed by hegemonic sectors linked at first to the Spanish ecclesiastical-monarchy administration and later, in the $19^{\text {th }}$ Century, linked to the government and the military corporation of Argentina. These imaginaries have been represented through different mythological incarnations around the figure of the devil that symbolized an alleged malignity of Chaco, and of which mythological narratives have been arranged, projecting a bicephalous logic of explanation/resolution to the mentioned negativity. In the $20^{\text {th }}$ Century, subaltern indigenous sectors of Chaco, produced, in turn, a mythological narrative that gave new meanings with a different direction to the previous demoniacal representations. This article's objective is to describe and explore analytically the cultural logics that imply the configuration of these different "myth-logics of the devil". This work highlights the necessarily historic nature of the myths and the centrality of power as a constitutive dimension of the mythological narratives created in the Argentinean Chaco about the different demoniacal characters that appear over the centuries as incarnations of a particular rhetoric of hegemonies and subalternities.

KEYWORDS: devil; myth; History; indigenous peoples; Argentinian chaco.

\section{Introducción}

La región del Chaco es un extenso territorio de llanuras boscosas que se extiende desde el sur de Brasil hasta el centro de Argentina, cubriendo buena parte de Bolivia y Paraguay. Siendo un área geográfica de gran importancia en América Latina, al igual que los Andes y la Amazonía, los imaginarios sociales que históricamente se han configurado sobre el Chaco lo describen como una geografía imaginaria (SAID, 2002) extraordinariamente agreste y salvaje, pero al mismo tiempo poseedora de riquezas inconmensurables. Estas representaciones que figuran al Chaco como un territorio inhóspito, favorecieron la aparición de diversas narrativas míticas sobre la presencia del diablo, antiquísimo personaje mítico en la tradición judeocristiana. En el caso del Chaco Argentino, los mitos en torno a la figura del demonio han sido producidos en distintas épocas y por 
actores sociales extremadamente disímiles: misioneros europeos, militares criollos y grupos indígenas.

Si como enunciara Claude Lévi-Strauss (1995), la sustancia de los mitos no se encuentra en el estilo, ni en el modo de la narración, sino más bien en la historia que ellos relatan, el análisis de los mitos permitirá descubrir las lógicas que operan en la producción de los mismos. Precisamente el mito, en el sentido antropológico del término, lejos de ser una mera secuencia narrativa quimérica o ingenua, encarna la interpelación/resolución de un problema existencial de la sociedad en su conjunto y se constituye como el apoyo narrativo de las creencias de un grupo, en la medida en que la historia que narra tiene un sentido resolutorio para alguno de los conflictos internos. Lamentablemente, los análisis antropológicos más extendidos acera de los mitos se han encargado de invisibilizar las relaciones de poder que en ellos se plasman, manifestando un desinterés por el origen histórico del mito, así como por determinar quiénes y por qué lo (re)producen (WOLF, 2001). De esta manera, la propia perspectiva lévi-straussiana que concibe a los mitos como estructuraciones narrativas constituidas a partir de oposiciones binarias producidas en última instancia por un proceso biológico cerebral, ha opacado el examen de la creación de los mitos como dispositivos de producción de subjetividades, estructurados socialmente dentro de unas particulares e históricas relaciones de poder.

Analizar las mitologías -necesariamente históricas- producidas en y sobre el Chaco Argentino, implica redimensionar la tesis del "autonomismo cultural" y reconocer los nodos de estructuración del poder que han configurado dichas narraciones. Como veremos, los ejercicios de colonización del Chaco y la producción de imaginarios sobre el demonio están íntimamente ligados a una compleja trama de relaciones de dominación, explotación y conflicto propias de la colonialidad del poder (QUIJANO, 2000), acaecidas en la región al menos desde el siglo XVII. A partir de los mitos que recrean de diversas formas la presencia del diablo en el Chaco Argentino, esperamos aproximarnos a las lógicas generadoras de cada una de dichas narrativas.

Para alcanzar lo anterior, la primera parte del trabajo desarrolla una descripción espacio-temporal breve -pero necesaria- del Gran 
Chaco, haciendo hincapié en lo que geopolíticamente se denomina Chaco Argentino y utilizando la categoría de formación social de fronteras para caracterizarlo. A partir de aquí las tres secciones que continúan, exploran las diferentes "variantes" míticas en torno a la figura del demonio en el Chaco Argentino, estas secciones se organizan cronológicamente en tres fases: 1) El mito del Diablo en la última época colonial a mediados del siglo XVIII, 2) El mito del Demonio en el periodo formativo del Estado-Nación a fines del siglo XIX, y 3) El mito del Familiar durante la etapa contemporánea a principios del siglo XX. Finalmente, la última sección intenta encontrar las lógicas subyacentes a la producción de los tres mitos anteriores enmarcados en la época de su producción.

\section{Caracterización histórica del Chaco Argentino}

La región sudamericana conocida como el Gran $\mathrm{Chaco}^{2}$ constituye un área territorial muy extensa cuya dimensión alcanza aproximadamente $1.200 .000 \mathrm{~km}^{2}$, comprendiendo geográficamente parte del Sureste de Brasil, el Oeste de Paraguay, el Este de Bolivia y el Centro-Norte de Argentina. En su conjunto, el Gran Chaco constituye una extensa Ilanura aluvial, ubicada al Este del piedemonte andino, ocupando la gran depresión que abarca desde el Norte de Sudamérica entre los plegamientos andinos y subandinos, y el cratín brasilico. Fitogeográficamente el Chaco está dominado por un bosque xerófilo, cuyo relieve es casi plano con una leve pendiente en el sentido NoresteSuroeste. Desde el punto de vista geomorfológico, el diseño fluvial es anastomosado, aunque en la actualidad persisten los denominados paleocauces o antiguos ríos que conformaban madrejones y que al día de hoy se conectan a una red de drenaje durante la estación lluviosa del verano.

Generalmente la región del Gran Chaco es subdividida de Norte a Sur en tres grandes zonas: 1) el Chaco Boreal, que envuelve por completo la región sub-amazónica de Brasil, todo el Oeste de Paraguay

\footnotetext{
${ }^{2}$ La palabra Chaco es un vocablo del antiguo Quechua, cuyo significado podría ser traducido como "territorio de la cacería".
} 
y buena parte del Este de Bolivia comprendiendo secciones de los departamentos de Tarija, Chuquisaca y Santa Cruz. 2) el Chaco Central, que se inicia en el río Pilcomayo (el cual representa el accidente geográfico que marca los límites fronterizos entre Argentina, Paraguay y Bolivia) extendiéndose hacia el sur hasta el río Bermejo, abarcando así prácticamente la totalidad de la provincia de Formosa y todo el noroeste de la provincia de Salta en Argentina. 3) el Chaco Austral, que se extiende en el norte desde la cuenca del río Bermejo hasta el río Paraná al sur donde finaliza, englobando así la totalidad de las provincias del Chaco y de Santiago del Estero, gran parte del este de la provincia de Tucumán, el sureste de la provincia de Salta y el norte de la provincia de Santa Fe, en Argentina.

Figura 1 - Mapa del Chaco central en Argentina.

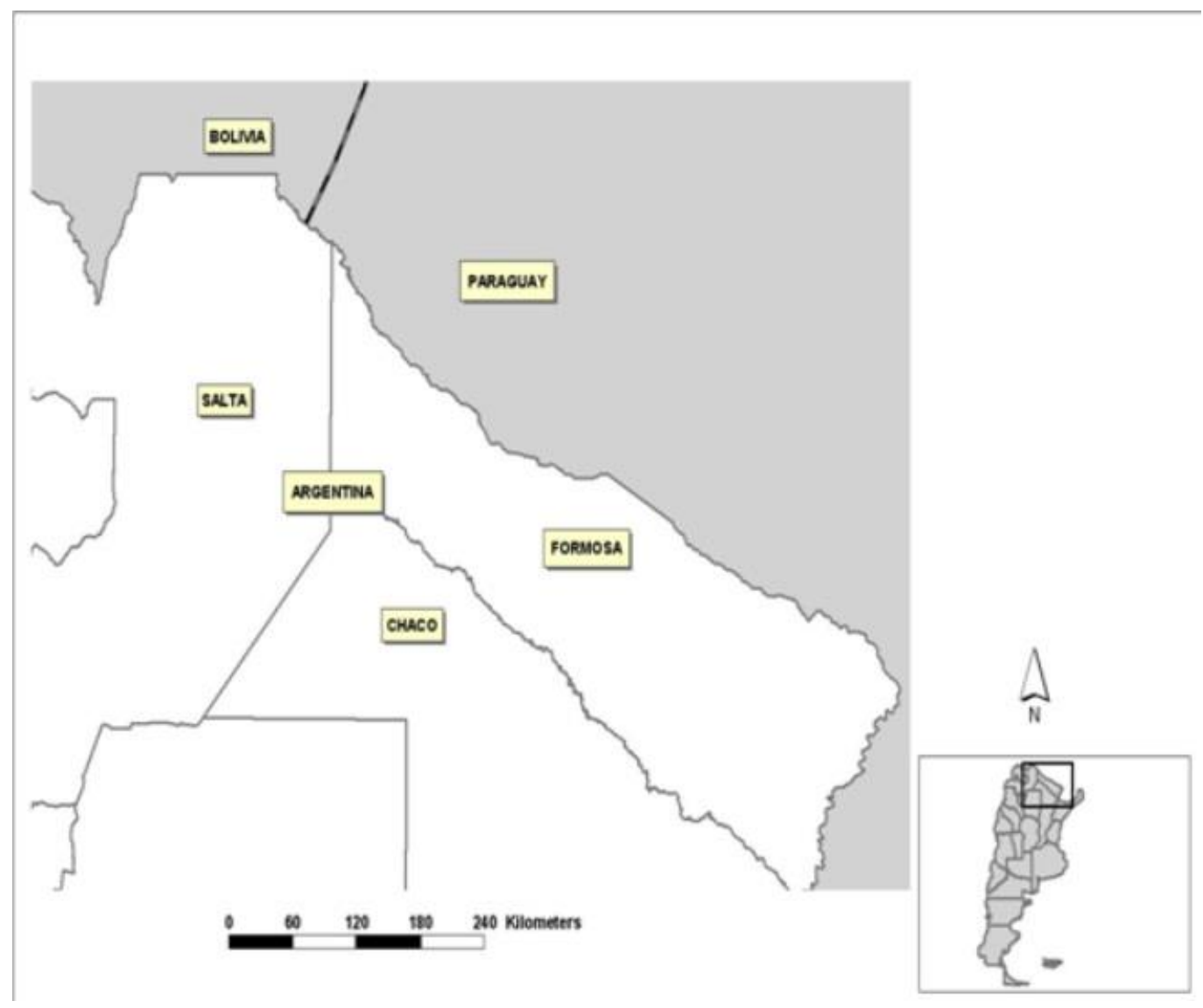

Fonte: Quintero (2012).

De aquí en más, cuando hablemos del Chaco Argentino estaremos refiriéndonos a las zonas del Chaco Central y Austral, las cuales 
representan el $22 \%$ del territorio continental del país, además del área forestal más importante de Argentina, a pesar de la descarnada deforestación a la que ha sido sometida en los últimos lustros.

La historia moderna del Chaco, es la historia de un territorio en permanente disputa, los sentidos que le han sido atribuidos siempre han estado signados por la ambigüedad representacional de un territorio extremadamente periférico, pero al mismo tiempo, de vital importancia, tanto bajo el domino del corona española como dentro del Estado-Nación Argentino. Para caracterizar al Chaco y otros territorios que fungen como "patio trasero" de la modernidad, es útil recurrir a la noción de formación social de fronteras (TRINCHERO, 2000). Con esta categoría se pretenden caracterizar territorios heterogéneos de una alta complejidad social, en donde se despliegan particulares relaciones de producción capitalistas expresadas en la conjunción de situaciones de construcción de fronteras políticas y culturales. Las dinámicas del Chaco nos permiten caracterizarlo como una formación social de fronteras, precisamente por ser un territorio en permanente disputa, donde se han gestado históricamente formas particulares de control y explotación del trabajo caracterizadas por la subsunción histórica del trabajo doméstico indígena, en un principio por parte de la Encomienda colonial y posteriormente por la apropiación de los obrajes e ingenios agroindustriales de la Argentina moderna. Asimismo, el Chaco funge como zona limítrofe entre cuatro Estados sudamericanos, constituyéndose como frontera cultural.

Como formación social de fronteras, el Chaco fue constantemente una zona de guerra y colonización. El primer intento por colonizar el Chaco se suscitó a mediados del siglo XVI al Oriente de la región del Chaco Boreal ubicada en las márgenes del río Paraguay, teniendo como epicentro la ciudad de Asunción administrada por la orden eclesiástica de los Jesuitas. Para esa época, la monarquía española estaba especialmente interesada en lograr controlar de manera efectiva esta región con el fin establecer una frontera segura que diera un alto a las ocupaciones de esas tierras por parte de los Bandeirantes de la Corona portuguesa. Al mismo tiempo, los "poderes coloniales locales" necesitaban con urgencia disponer de mano de obra en la zona. La segunda oleada de conquista de la región se gestó a finales del siglo XVI 
en el norte de Tucumán, al Suroeste del Chaco Austral. Este segundo intento tenía como objetivo restablecer y asegurar el Camino Real de Potosí, que atravesando el Chaco pondría en contacto los virreinatos de Perú y La Plata (TRINCHERO, 2000). Ambos ejercicios de colonización implicaron intentos por reducir y controlar a los pueblos indígenas de la región, ya sea por la vía del genocidio o por la adhesión forzada al marco jurídico establecido por el régimen de la Encomienda. En este último caso era necesaria la fundación de ciudades y el establecimiento de misiones que fueron construidas desde finales del siglo XVI hasta mediados del siglo XVII. Las guerras y escaramuzas entre el virreinato y los pueblos indígenas, que se gestaron desde el inicio de la colonización del Chaco, ocasionaron no sólo la expulsión de los conquistadores, sino que además fueron incendiadas hasta quedar en ruinas, casi todas las ciudades y asentamientos misionales que habían sido establecidos (TERUEL, 2005).

A fines del siglo XVII el imperio español modificó su estrategia de colonización del Chaco llevando a cabo grandes campañas militares para doblegar a las dos principales etnias que habían arrasado los asentamientos otrora fundados. Desde Asunción, la primera campaña se despliega contra los Guaycurú asentados en el Noreste del Chaco, y la segunda campaña se realiza desde Tucumán contra la etnia Mocoví. Los resultados de dichas incursiones si bien lograron reducir tanto la población aborigen como el territorio controlado por las mismas, no pudieron concretar un dominio efectivo del Chaco. Sólo es a mediados del siglo XVIII, que con la fundación de ciudades, el establecimiento de pactos con algunos grupos indígenas y el éxito de varias misiones en conseguir adeptos, que se consuma la ocupación efectiva de algunos pocos espacios chaqueños (WRIGHT, 2003). Para el caso de los principales frentes de expansión colonial; en el Chaco Boreal, los jesuitas tuvieron un mayor éxito para cristianizar a la población indígena Guaycurú e incorporarla a la Encomienda, mientras que en el Suroeste del Chaco Austral la población Mocoví se opuso con más ahínco a la asimilación de la sociedad colonial.

La postura débil y dispersa que mostró la Corona española para con el Chaco en la época de su dominio, vendría a ser modificada por el naciente Estado-Nación argentino en el ejercicio de su 
autoconstrucción. Así como para España la conquista del Chaco permitiría proteger los dominios de la Corona frente a los propósitos del imperio portugués, para el Estado-Nación que acababa de lograr su independencia, el control del Chaco posibilitaría el establecimiento claro de sus fronteras con los demás países de la región. No obstante, para logar tal cometido el Estado argentino configuró una frontera imaginaria interna con los pueblos indígenas, sostenida en términos de la dicotomía decimonónica de civilización y barbarie. Siendo así definida la geografía de la barbarie por los territorios del Chaco Austral, y por la región del Chaco Central que representaba la "última frontera" interna de la nación no civilizada. Frontera interna que sería conquistada de manera efectiva en el año de 1911, con la incursión militar dirigida por el General Enrique Rostagno.

La estrategia aplicada por el Estado argentino para la colonización del Chaco, estuvo basada en la construcción de fortines a lo largo de los ríos Bermejo y Pilcomayo, y en las incursiones militares que desde 1870 -año que podríamos marcar como el inicio del proceso de la conquista del Chaco- se dieron en la región. Estas incursiones militares tuvieron otros motivos además del control territorial del Chaco Austral y Central. Al expandirse la frontera interna de la nación, una tarea primordial del Estado era poblar las áreas que estaban "despobladas", en realidad ocupadas con anterioridad por pueblos indígenas y que desde 1883 comenzaron a ser pobladas por colonos criollos que fundaron en su mayoría plantaciones de algodón y obrajes azucareros (CORDEU y SIFFREDI, 1971). Ambos emprendimientos necesitaban la provisión de mano de obra que sólo podía ser suministrada por indígenas. He aquí uno de los motivos medulares por el cual la población indígena del Chaco Argentino no fue totalmente exterminada por las incursiones militares estatales, pues dicha población era necesaria para el desarrollo de las plantaciones y obrajes. Así, desde 1917 con el control territorial ya consumado, el ejército posicionado en los distintos fortines del Chaco, comenzó a reclutar de manera forzada a indígenas como mano de obra para estos emprendimientos (TRINCHERO, 2000).

De esta manera, la ocupación del Chaco Argentino, por parte de las fuerzas militares del Estado-Nación, tuvo como resultado la desintegración de las formas de vida de las comunidades indígenas 
chaqueñas (WRIGHT, 2003). Tales pueblos desde ese entonces quedaron supeditados a las dinámicas del capitalismo nacional agroexportador, fungiendo como trabajadores estaciónales y como obreros desde principios del siglo XX (IÑIGO CARRERA, 1983), situación que se mantiene hasta la actualidad.

\section{El Diablo cristiano en el periodo colonial}

Para adentrarnos en el mito del Diablo, producido por el imaginario cristiano y misional del periodo colonial en el Chaco Argentino, entre principios del siglo XVII y mediados del siglo XIX, tenemos como referencia el legado testimonial del Fray Pedro Lozano, quien formó parte de las infructuosas expediciones misionales al Chaco durante principios del siglo XVIII. Es evidente que el relato presente en la obra de Pedro Lozano es la concreción de décadas de narrativas sobre el Diablo (MUCHEMBLED, 2002) y la escogencia por parte de éste del Chaco como su lugar de residencia. Sin embargo, la principal fuente que relata el mito sobre la presencia del Diablo en el Chaco Argentino data precisamente de 1733 con la historia descrita por Lozano. A quien citaremos extensamente, transcribiendo los pasajes en donde relata la llegada del Diablo a los territorios del Chaco, o sí se quiere el "mito de origen" de la presencia del Diablo en esta región, que, como se verá, es al mismo tiempo la explicación del origen de la población indígena en el Chaco. Según Lozano, y las narrativas míticas de la época, el Diablo estaba en contacto constante con los indígenas, manteniendo entre ellos reuniones muy frecuentes, un día durante uno de estos encuentros:

El Diablo muy triste y pesaroso, les hacía saber [a los indígenas], que 'muy pronto entrarían en su tierra, una gente desconocida, valiente, belicosa y enemiga capital de los indios, contra la cual habían estado batallando en todas partes, sin fruto, aquellos cuatro años en que habían enmudecido sus oráculos; que aquellas gentes conquistarían y se harían señores absolutos y despóticos de su tierra, de sus mujeres, de sus hijos, y aún de su propia libertad, abusando de todo según su antojo, y tratándolos a todos ellos como suyos, y aún quizás peor, porque una vez que ellos metan el pie en 
esta provincia, como sin duda lo meterán a su tiempo, por más que yo os quiera ayudar, no les podréis resistir, pues no se quien les ampara y favorece que hallo flacas y débiles mis poderosas fuerzas y las de todos mis secuaces para contrastarles, como lo he experimentado con pérdidas de mis soberanas adoraciones en otras provincias remotas donde con todo mi poder les he hecho en vano cruda guerra, pues en todas me han despojado de mis antiguos sacerdotes, me han derribado los adoratorios y templos más célebres, suntuosos y frecuentados de devotos míos, que acudían a invocarme, me han ahuyentado con no se que encantos, contra lo que no tengo modo de oponerme. Si esto ha hecho conmigo, que harán con vosotros, flacos y miserables'. Hizo pausa el Diablo, para ver los efectos que obraban sus diabólicas razones encaminadas a que por huir de tamaños males, se retirasen a partes donde no pudiese penetrar el poder español, y por consiguiente, ni la luz evangélica que venían comunicando a todo este hemisferio. Hizo, como decía, pausa el Diablo en su razonamiento y luego que cesó de hablar, como tan infaustas nuevas habían atravesado de dolor sus corazones cobardes, prorrumpió el innumerable auditorio, que le escuchaba, en llantos y gemidos, que ponían en el cielo, llorando inconsolablemente su desventura. Acompañándoles el Diablo con singulares demostraciones de sentimiento y compasión para tenerlos más de su parte, y volviendo a tomar la mano, y haciendo silencio prosiguió y les dijo: cierto es todo lo que os he anunciado, como lo experimentará en breves términos quien, desatendiéndose al amor que os profeso, despreciare mis consejos; justo será que padezca tamañas miserias quien con una fácil resolución las pudo evitar todas, siguiendo mi parecer'. Así, concluyo su razonamiento el Diablo, y deponiendo la figura humana, en que hasta allí se había dejado ver, y les había hablado, se transformó de repente en un furioso huracán, que se fue encaminando a la provincia del Chaco, a donde le fueron siguiendo los más de aquella numerosa junta, animados de los hechiceros ministros fieles del demonio, y otros muchos de la provincia del Tucumán a donde llegó la fama de este suceso, y allí quedaron los miserables sepultados hasta ahora en las tinieblas de la infidelidad, sin esperanzas de salir de ellas hasta que Dios se compadezca; y de aquí provino hallarse aquella provincia tan poblada, y mucho más, cuanto más se va retirando de la tierra de españoles, como diremos (LOZANO, 1989, p. 59-60). 
Sin duda la reconstrucción de las narrativas míticas de la época que realiza Lozano, está influenciada por la tradición ficcionaría de las academias eclesiásticas de Salamanca, cuyos frailes distribuyeron por toda América. En esta tradición, la figura del diablo se asienta en las cadenas narrativas medievales originadas en Medio Oriente, y trasladadas prontamente a Europa, en donde el diablo se recrea como uno de los personajes principales del "mito del combate primordial". Conflicto sangriento entre seres sobrenaturales que representan al bien y al mal, que se dirime gracias a la expulsión definitiva del espacio celestial (o extraterrenal) del personaje maligno, el cual tomará la tierra como lugar donde procurarse un imperio a través de la seducción de los mortales (FORSYTH, 1989).

No obstante, la historia relatada por Lozano, que incluye también ciertos mitemas en torno a los augurios de la presencia de los españoles en América, nos muestra una recopilación bastante representativa del mito del Diablo en el Chaco para la época de la Colonia. En este sentido es necesario considerar, tal como lo sostiene Robert Muchembled (2002), que la diseminación del mito del demonio es directamente proporcional a la propia expansión del colonialismo europeo. En el momento preciso en que Europa buscaba una coherencia identitaria interna de la mano de un sistema religioso más consistente y homogéneo, que se valió de diversas instituciones para lograr este fin. Tal vez la Santa Inquisición, institución encargada de perseguir las manifestaciones diabólicas y la brujería en la Tierra, sea la más representativa de estas instituciones.

Bajo los nuevos modelos de relaciones societales que se expresan en la solidificación de las bases institucionales del poder eclesiástico, la amenaza del diablo y del infierno sirve como un mecanismo de cohesión social, articulando un correlato de mandato celestial con una expansión y conquista terrenal de almas y territorios. No es casual que en los imaginarios del diablo producidos durante la conquista de América, el personaje mítico suela residir muy comúnmente en recónditos espacios que esperan ser dominados por los colonizadores (MUCHEMBLED, 2002). 


\section{El Demonio criollo en la formación del Estado-Nación}

Como hemos descrito con anterioridad, la colonización del Chaco por parte de las fuerzas militares del Estado-Nación Argentino, que se llevó a cabo desde finales del siglo XIX hasta principios del siglo XX, supuso la conquista y anexión definitiva de estos territorios por parte de la organización estatal central. En esta época las narraciones míticas sobre el Diablo fueron producidas principalmente por los milicianos del ejército argentino que llevaron a cabo la conquista y colonización del Chaco. En este sentido, el mito del Demonio, no se refiere a la presencia del Diablo como personaje cristiano, sino más bien a la existencia de un ser más difuso: el "Demonio", que como una entidad maligna con la capacidad de poseer las almas de los indígenas, generan en ellos comportamientos belicosos hacia las tropas estatales que intentaban reducirlos por la fuerza.

Para la reconstrucción del mito del Demonio nos basaremos en un texto escrito por el Teniente Coronel Jorge Luis Fontana, cuya primera edición data de 1881. Dicho texto relata las "aventuras" de Fontana en 1880 , cuando dirigió una de las campañas de conquista en el Chaco Austral. A diferencia, del estilo narrativo y mítico de Lozano, Fontana está ampliamente influenciado por el pensamiento positivista de la época que dominaba a la elite intelectual latinoamericana, por ende, su texto está más cercano a las descripciones etnográficas que a los relatos fantásticos de otros siglos. Fontana está interesado en descubrir las razones del "carácter belicoso de los indios del Chaco que les impide ver las bondades de la civilización que la nación trae a ellos" (FONTANA, 1977, p. 97).

La historia relatada por Fontana comienza por descartar de toda "lógica" las aseveraciones del Fray Pedro Lozano, por estar sustentadas en "habladurías y supersticiones religiosas" (FONTANA, 1977, p. 39). Al estar influenciado por el positivismo que dominaba el ámbito intelectual de la época, el primer ejercicio discursivo de Fontana es diferenciarse de las narrativas religiosas o no científicas, para así sustentar, a través de la guía de la ciencia, que el conocimiento que él ha obtenido y que ahora comunica en su texto es objetivo y verdadero. Desde aquí Fontana describe geográficamente la zona del Chaco Argentino a la vez que 
argumenta la importancia de este vasto territorio para la nación. En seguida, Fontana discurre en relatar las estrategias militares desarrolladas para la conquista del Chaco y la "pacificación" de los indígenas chaqueños. En este punto Fontana expone sus ideas antropológicas sobre los grupos indígenas del Chaco, mostrando y describiendo a cada una de las diferentes etnias indígenas que en ese entonces habitaban la región. Al igual que los primeros intentos disciplinarios de la antropología de mediados del siglo XIX, las descripciones antropológicas de Fontana estaban más interesadas en describir rasgos físicos y raciológicos, como la capacidad craneal y el color de la piel, que los modos de vida cultural y social de dichas poblaciones.

No obstante, en algunos pasajes de su obra se atreve a especular sobre las "costumbres" indígenas en el manejo de las armas y en la crianza de los niños. He aquí cuando aparecen las referencias al carácter "endemoniado" del comportamiento indígena, esta vez sorprendentemente, retomando a Fray Lozano:

..Puede que las supersticiones del Diablo de Pedro
Lozano hayan sido erradas, pero si en algo el sacerdote
acertó es sin duda en que los indios de estas tierras
poseen una conducta endemoniada que los hace actuar
desaforadamente sin escuchar razón alguna. Tal vez
por ello muchos de los colonos y de las fuerzas
milicianas, e incluso yo mismo he llegado a pensarlo,
creen que los indios están poseídos por el espíritu del
demonio que los hace comportarse así y los liga a la
barbarie pues ningún hombre sano que conozca la
civilización puede tener ese tipo de conducta"
(FONTANA, 1977, p. 154).

Lo que realiza Fontana en el extracto anterior es revelarnos la existencia de una creencia compartida, un mito entre los criollos de la región chaqueña (colonos y militares) sobre la presencia del Demonio, no como el "rey del infierno" como aseguraba la tradición cristiana descrita por Fray Pedro Lozano, sino esta vez, como un Demonio secularizado en forma de un espíritu que posee a los indígenas, obligándolos a comportarse salvajemente. En este orden, el mito remite a una producción común decimonónica donde el Diablo es representado no en pocas ocasiones como un "hombre salvaje" (MUCHEMBLED, 2002). 
Pero más importante y profundo aún parece ser, en la versión de Fontana, esa disposición diabólica mediante la cual el Demonio de su relato (compartido ampliamente por los militares de la conquista del Chaco) tiene la capacidad de poseer los cuerpos de los indígenas chaqueños para hacerlos actuar de forma "endemoniada", lejos de la razón y en oposición clara a las fuerzas de la civilización. Así, el Demonio sería en última instancia el responsable de la barbarie indígena en el Chaco.

Estamos en presencia de una transformación del discurso mitológico de Diablo que sitúa la malignidad demoniaca al interior de los cuerpos. Al tiempo que se corporiza la influencia negativa del demonio en las personas, se descorporiza al Diablo mismo como personaje. Esto instiga culturalmente a la represión individual y al control social de la malevolencia propia del sujeto que sólo puede regularse a través de la represión de instintos y pasiones (MUCHEMBLED, 2002).

\section{El Familiar indígena en la época contemporánea ${ }^{3}$}

El mito indígena del Familiar se gesta paralelamente a la fundación de los obrajes e ingenios agroindustriales en el Chaco Argentino, en donde trabajó desde principios del siglo XX $-\mathrm{y}$ hasta la actualidad- gran parte de la población indígena, en condiciones extremas de explotación. Como se ha dicho con anterioridad, la colonización del Chaco por parte de las fuerzas militares argentinas conllevó la asimilación de las poblaciones de dichos territorios al nuevo ordenamiento impuesto por el Estado-Nación, que para el caso de la población indígena supuso la subsunción de su trabajo doméstico por parte del capitalismo agroindustrial.

Las narraciones míticas en torno al Familiar poseen diferentes versiones o variantes (en el sentido levistraussiano), quizás porque la

\footnotetext{
${ }^{3}$ A diferencia de la exposición de los mitos anteriores, que fueron presentados cada uno mediante una fuente histórica, el mito indígena de El Familiar será reconstruido aquí por las reseñas que hacen de dichas narrativas Gordillo (2006) y Trinchero (2007). Así como por las notas recogidas en el trabajo etnográfico del autor (Quintero, 2012) en el Chaco Central durante diversos periodos entre Julio de 2006 y Abril de 2012.
} 
producción de dicho mito recorre un área geográfica muy extensa, más aún considerando que esta zona es habitada por trece etnias indígenas diferentes que precisamente han sido las productoras del mito ${ }^{4}$. Esto último puede tal vez explicar que en el idioma castellano, el personaje principal del mito sea denominado El Familiar, palabra que designa al personaje de una antigua leyenda del Medioevo Europeo, y que representa también la nomenclatura originada en los siglos XIV y XV para denominar diferentes entidades que, a manera de mascotas malignas, acompañaban a las brujas y hechiceros. Casi siempre en forma de animales, en estos "familiares" residían espíritus demoniacos que protegían y colaboraban con los supuestos servidores humanos del diablo.

Se puede reconstruir el mito de El Familiar de la siguiente manera: El Familiar es un habitante del Chaco, llevado allí por los criollos dueños de los ingenios y obrajes que han realizado con él un pacto de sangre para el crecimiento de sus empresas y de su dinero. El Familiar tiene la capacidad de cambiar de forma, pero comúnmente se presenta como un perro negro muy grande (a veces sin cabeza) que al desplazarse emite un sonido que se asemeja a unas cadenas a rastras. Tiene la capacidad sea cual sea su transformación- de echar fuego por los ojos y la boca. También se le ha visto con otras transmutaciones, como la de un hombre de mediana edad muy apuesto y elegante, o como una enorme serpiente negra y peluda. Los dueños de los obrajes pactan con El Familiar para obtener ganancias extraordinarias en sus industrias, a cambio le otorgan uno o varios peones indígenas para que éste los devore, saciando su anhelo natural de comer gente. Por lo general El Familiar devora un peón indígena al año, pero a veces a llegado a comer tres o cuatro. Aunque se supone que el Familiar camina con libertad entre los ingenios y obrajes, no puede atacar a ningún peón y devorarlo sin la participación o el permiso del dueño de los campos e industrias (GORDILLO, 2010). Éste último le señala a El Familiar cuál persona indígena puede comerse, y le tiende una trampa al peón enviándolo a buscar una herramienta especial o a limpiar un sector desconocido del

\footnotetext{
${ }^{4}$ Estas etnias indígenas que habitan históricamente el Chaco Argentino son: Chané, Chiriguano, Chorote, Chulupí, Diaguita-Calchaquí, Mbya-Guaraní, Kolla, Mocoví, Nivaklé, Pilagá, Tapiete, Qom (Toba), y Wichí.
} 
monte (TRINCHERO, 2000). Estando el peón indígena en el lugar indicado, El Familiar sorpresivamente lo ataca para finalmente devorarlo vivo.

Algunas variantes del mito, reseñan que una vez alguien sobrevivió al ataque de El Familiar. Se supone que el peón en cuestión, además de ser un indígena muy valiente y recio que nunca acataba las órdenes del patrón (razón por la cual el dueño del ingenio lo señalo como comestible a El Familiar), llevaba consigo una cruz al cuello y un rosario en el bolsillo, objetos que espantaron al Familiar. En este caso, el dueño del obraje o el ingenio debió saciar con otro indígena el hambre de El Familiar, pues si no él mismo sería devorado, y el dinero que había acumulado desde la llegada de El Familiar desaparecería o se convertiría en polvo (GORDILLO, 2006).

Para aplacar el hambre de El Familiar, el mito fue acompañado por un ritual entre los indígenas trabajadores de los ingenios y obrajes, que se realiza con el fin de evitar la muerte de alguno de los peones indígenas del emprendimiento. El ritual se lleva a cabo los días posteriores a la cosecha agrícola y consiste en dejar en el ingenio un muñeco que representa a un peón. Se supone entonces, que El Familiar devorará al muñeco y así saciara su hambre hasta el año siguiente. Otros indígenas más arriesgados insertan peticiones dentro del muñeco que será devorado por El Familiar, con la esperanza de que éste arregle algún negocio especial con ellos o establezca un pacto de otro tipo.

Además de la evidente memoria de explotación y subordinación que el mito de El Familiar recrea con nitidez (GORDILLO, 2010), este relato y su posterior ritualización, da cuenta de un proceso de dislocación de las características comunes del Diablo. Se encuentra en este caso una narración personificada por una figura central del Diablo con el cual se puede pactar e incluso derrotarlo a través de diferentes artimañas. Tal y como sostienen muy diversas tradiciones orales extendidas por buena parte de América Latina (TAUSSIG, 1980), nos encontramos en presencia de un Diablo terrenal, con fragilidades y debilidades que lejos de representar un poder por completo extraterrenal se asocia con malignidades humanas y terrenas, fungiendo como parte de específicas dinámicas de dominación y de explotación. 


\section{Mito-lógicas (históricas) del Diablo en el Chaco Argentino}

Para analizar los mitos que exploramos con anterioridad, es necesario remitirse al marco histórico de relaciones interétnicas en la que se imbrican los grupos y los sujetos productores de estos mitos. Relaciones interétnicas e históricas que deben ser examinadas como partícipes de una estructura social específica dentro del marco territorial del Chaco Argentino supeditado al desenvolvimiento del sistema-mundo moderno/colonial. Es evidente que cada uno de los mitos en torno a la figura del Diablo en el Chaco Argentino responde a un imaginario histórico y étnico específico, que a su vez inviste una productividad política.

El Diablo cristiano del período colonial es un mito producido por los misioneros españoles que está fuertemente arraigado en la tradición judeo-cristiana así como en algunas creencias míticas propias de la edad media. Siendo el Chaco un territorio desconocido, pero a la vez fundamental para los intereses de la Corona española frente a la expansión territorial portuguesa en el nuevo mundo, este fue imaginado por la mentalidad misionera como el último reducto del Diablo en el mundo terrenal. Asimismo, el Demonio criollo, secularizado por la imaginación positivista de la etapa formativa de la nación argentina, concibió la existencia del Demonio como explicación del comportamiento "endemoniado" de los grupos indígenas del Chaco en su resistencia a la "civilización" de la elite criolla.

Siguiendo a Lévi-Strauss, podemos apuntalar que "el objeto del mito es proporcionar un modelo lógico para resolver una contradicción" (LÉVI-STRAUSS, 1995, p. 252). La sustancia de los mitos del Diablo cristiano y del Demonio criollo se asientan en la necesidad -por parte de ambos grupos étnicos- de conquistar el Chaco; pero a su vez se fundamentan en la profunda dificultad de llevar a cabo esta empresa. Si como escribió Fray Pedro Lozano: "el aura divina de Dios cubre con su santidad toda la Tierra", ¿Por qué el Chaco aún no ha sido bendecido y poseído por esta santidad? He allí la contradicción que el cristianismo debe enfrentar en la narración mítica del Diablo. Para el caso de la corporación militar argentina del siglo XIX, si el Chaco es un territorio 
nacional de vital importancia para la constitución de un Estado civilizado ¿Por qué las fuerzas de la civilización no han podido anexarlo? Y en el mismo orden de ideas, ¿Por qué le es tan difícil a las fuerzas de la civilización dominar la barbarie (inferior) de los grupos indígenas chaqueños?, estas son las contradicciones prácticas que el mito del Demonio criollo viene a procurar disipar.

En la base circunstancial de ambos mitos el Chaco es un territorio a colonizar, en este sentido es clasificado como una región habitada por algún tipo de malignidad, que en última instancia explica lo inexpugnable del terreno y lo indócil de sus habitantes. Si algo demostró con claridad Edward Said en Orientalismo (2002), es que representar, imaginar, pensar sobre un territorio forma parte del ejercicio de dominarlo. En este sentido, tanto el mito cristiano de la época colonial sobre el Diablo como el mito del Demonio criollo en el período formativo de la nación, fungieron como sostén de los dispositivos de control territorial que intentaron subsumir al Chaco y a su población. No obstante, y aunque todos los mitos poseen una función pragmática, no debe pensarse en el origen de las narraciones míticas necesariamente como un discurso propagandístico configurado para someter poblaciones y territorios. Por el contrario, y a pesar de que estos mitos hayan servido como legitimadores de ciertas políticas hacia la región chaqueña, los mitos son tales porque están arraigados en las estructuras cognitivas, en los imaginarios sociales y en la memoria histórica de los pueblos que los conciben y reproducen. Es precisamente en este punto donde reside su "eficacia simbólica" (LÉVI-STRAUSS, 1995).

El caso del mito indígena de El Familiar es diferente a los anteriores, no sólo por la época de su producción y por los grupos étnicos que lo generaron, sino más importante aún por el sentido mismo de la narración mítica. Mientras que los misioneros españoles y los militares criollos estaban en una posición de hegemonía que pretendían ejercer sobre el Chaco, las comunidades indígenas se encontraban, y se encuentran aún hoy, en un estado de subalternidad frente a los demás grupos colonizadores. De esta manera, la cuestión que debe resolver el mito de El Familiar es la relación en contrapunto entre resistencia y subordinación que los pueblos indígenas del Chaco 
han desarrollado ante la hegemonía de las elites criollas. El Familiar, lejos de ser una figura que represente la suma de todas las malignidades (en el caso del Diablo cristiano) o la causante de la barbarie (para el mito del Demonio criollo), para los pueblos indígenas chaqueños constituye, por el contrario, un personaje mediador entre mundos de la comunidad cósmica y entre las diferentes colectividades de indígenas y criollos. Para los grupos de misioneros españoles y de militares criollos que generaron y reprodujeron el mito del Diablo, la única posibilidad de acción ante la comprobación de que éste -fuese cual fuese su forma- habitaba el Chaco, era la conquista del territorio y la erradicación de su maléfica presencia. En cambio, desde el punto de vista de las comunidades indígenas del Chaco, El Familiar, aunque temido aliado de los patrones criollos, representa una figura con la que se puede negociar para resguardar la vida, obtener algún bien deseado o restituir cierto orden.

Aunque hemos establecido las diferencias entre los distintos mitos sobre e Diablo en el Chaco Argentino, no deja de ser interesante que el mismo Diablo como personaje principal de estos mitos aparezca en ellos de forma tan similar, podría decirse, como un significante compartido o como una "forma" compartida en el sentido en que la entiende Roland Barthes (1980). Sin embargo, aunque la forma del mito es compartida o al menos muy similar al ser el demonio su figura principal, no pasa lo mismo con su significado o "concepto" (BARTHES, 1980), el cual es ampliamente diferente de acuerdo al mito. Una explicación posible para esclarecer el carácter común de la forma del mito, reside en que todos ellos han sido producidos con un imaginario territorial muy similar, al ser recreados en el Chaco: un espacio de conflicto, una formación social de fronteras que parece representar un ambiente adecuado para el despliegue de narrativas sobre lo malévolo. 
Figura 2 - Cuadro sinóptico de las mito-lógicas del Diablo en el Chaco Argentino.

\begin{tabular}{|c|c|c|c|c|}
\hline & $\begin{array}{l}\text { Productores del } \\
\text { Mito }\end{array}$ & $\begin{array}{l}\text { Época de Vigencia } \\
\text { del Mito }\end{array}$ & $\begin{array}{l}\text { Territorios del } \\
\text { Mito }\end{array}$ & $\begin{array}{l}\text { Carácter del } \\
\text { Personaje Mítico }\end{array}$ \\
\hline El Diablo & $\begin{array}{l}\text { Misioneros } \\
\text { Españoles }\end{array}$ & $\begin{array}{l}\text { Principios del S. XVII } \\
\text {-Mediados del S. } \\
\text { XIX }\end{array}$ & Gran Chaco & $\begin{array}{l}\text { Encarnación de la } \\
\text { maldad, a la } \\
\text { manera de la } \\
\text { tradición cristiana }\end{array}$ \\
\hline El Demonio & $\begin{array}{l}\text { Militares y } \\
\text { Colonos } \\
\text { Argentinos }\end{array}$ & $\begin{array}{l}\text { Mediados del S. XIX } \\
\text { - Principios del S. } \\
\text { XX }\end{array}$ & $\begin{array}{c}\text { Chaco Central y } \\
\text { Austral }\end{array}$ & $\begin{array}{l}\text { Manifestación de } \\
\text { la Barbarie, según } \\
\text { la elite argentina }\end{array}$ \\
\hline El Familiar & $\begin{array}{c}\text { Grupos Indigenas } \\
\text { del Chaco }\end{array}$ & $\begin{array}{l}\text { Principios del S. XX } \\
\text {-Época actual }\end{array}$ & Chaco Central & $\begin{array}{l}\text { Mediador entre } \\
\text { mundos, según el } \\
\text { imaginario los } \\
\text { grupos indigenas } \\
\text { del Chaco }\end{array}$ \\
\hline
\end{tabular}

Fonte: Elaboración propia.

Esta lógica también pude revelar las razones de la muerte de los mitos del Diablo de los misioneros y de los militares criollos, los cuales en la actualidad no son narrativas vigentes, pues únicamente conocemos su existencia y sus formas de operar en épocas anteriores mediante fuentes históricas. Un mito muere cuando pierde sentido la historia que él relata (LÉVI-STRAUSS, 1997), esta historia relatada por el mito puede derogarse al resolverse la contradicción que él intentaba zanjar. En el caso del mito del Diablo que procuraba resolver la contradicción alrededor de la imposibilidad de conquistar y evangelizar al Chaco y a su población, a pesar de que los productores del mito representaban las verdades incuestionables de la $\mathrm{Fe}$; el mito pierde sentido al dejar de existir la relación colonial entre España y la recién fundada Argentina, en ese momento el Chaco deja de ser un territorio 
donde debe operar la iglesia católica española pues ya no pertenece a la jurisdicción del imperio. De esta manera, el mito del Diablo muere al perderse el nicho territorial y la geografía imaginaria que lo sustentaba, la contradicción fundamental no se resuelve, pero la imposibilidad de conquistar el Chaco deja de ser en si misma una contradicción.

Al igual que el Diablo cristiano, el mito del Demonio criollo proponía disipar la contradicción de la dificultosa empresa de colonizar al Chaco por parte de la corporación militar que representaba -en este caso- las verdades inobjetables de la civilización. Al lograr anexionar y dominar por completo la región chaqueña, el mito producido y reproducido por los militares y colonos argentinos perdió su sentido original al ser los pueblos indígenas controlados política y militarmente por el Estado, y al estar subsumido su trabajo doméstico a través de los emprendimientos agroindustriales. La historia del Demonio poseyendo indígenas para que estos se comportaran de manera feroz resistiéndose a la civilización, debe haber resultado casi risible a principios del siglo XX cuando esta resistencia termino de manera definitiva.

Sí los mitos del Diablo cristiano y del Demonio criollo han muerto al haber perdido sentido la historia que relataban, o al haberse resuelto las contradicciones que intentaban solventar, no ha ocurrido lo mismo con el mito de El Familiar que sigue vigente al estar aún presentes las condiciones de dominación y de explotación que lo originaron. La historia que el mito relata sigue teniendo sentido al permanecer los grupos indígenas en una relación de subalternidad que se aferra a un mediador mítico, con el fin de zanjar la contradicción originaria entre resistencia y subordinación ante el capitalismo agrario y ante la hegemonía del Estado-Nación argentino.

Michael Taussig (1980) ha sostenido en base a sus investigaciones de campo en Sudamérica, que los mitos asociados al Diablo y a las figuras demoníacas en general, contienen un cuestionamiento crítico hacia las dinámicas de acumulación y explotación propias del capitalismo. No obstante, las mito-lógicas históricas producidas en el Chaco Argentino en torno a la figura del demonio, presentan un carácter más complejo, heterogéneo y discontinuo que el presentado por Taussig. Para el caso del Chaco, los mitos demoniacos, no varían exclusivamente por la temporalidad de su producción, sino como hemos 
visto, se diferencian entre si, por su carácter y fundamentalmente por los sectores que los han (re)producido. Si bien, el mito de El Familiar, está profundamente ligado a las hondas experiencias de control del trabajo indígena, difícilmente pueda ser reducida la complejidad de este mito únicamente a una representación/encarnación conciente de las ignominias del capitalismo.

Un sendero de reflexión posible, y un punto de partida para el análisis de estas presencias mito-lógicas similares estructuradas en torno al Diablo en el Chaco Argentino, es emprender exploraciones relacionales que reconozcan y se encarguen de las relaciones y tramas societales configuradas por los diferentes grupos que produjeron estos mitos diabólicos. Abrir el panorama de las exploraciones sobre los mitos a un ámbito de conexiones y relaciones temporal y espacialmente más amplio, puede darnos la clave para comprender mejor el nacimiento y la muerte de los mitos en contextos atravesados por el poder de la colonialidad.

\section{Referencias bibliográficas}

BALANDIER, Georges. Antropo-Lógicas. Barcelona: Península, 1975.

BARTHES, Roland. Mitologías. Ciudad de México: Siglo XXI, 1980.

CORDEU, Edgardo; SIFFREDI, Alejandra. De la algarroba al algodón: movimientos milenaristas del Chaco Argentino. Buenos Aires: Juárez, 1971.

FONTANA, Jorge Luis. El gran Chaco. Buenos Aires: Solar Hachette, 1977.

FORSYTH, Neil. The old enemy: Satan and the combat myth. Princeton: Princeton University, 1989.

GORDILLO, Gastón. En el gran Chaco: antropologías e historias. Buenos Aires: Prometeo, 2006.

Lugares de diablos: tensiones del espacio y la memoria. Buenos Aires: Prometeo, 2010. 
IÑIGO CARRERA, Nicolás. La colonización del Chaco. Buenos Aires: CEAL, 1983.

LÉVI-STRAUSS, Claude. Antropología estructural. Barcelona: Paidós, 1995. Antropología estructural dos. México: Siglo XXI, 1997.

LOZANO, Pedro. Descripción corográfica del gran Chaco gualamba. Tucumán: Universidad Nacional de Tucumán, 1989.

MUCHEMBLED, Robert. Historia del diablo: Siglos XII-XX. México: FCE, 2002.

QUIJANO, Aníbal. Dominación y cultura. Lima: Mosca Azul, 1980.

. Colonialidad del poder, cultura y conocimiento en América Latina. Anuario Mariateguiano, Lima, v. 9, n. 9, p. 113-121, 1997.

Colonialidad del poder y clasificación social. Journal of World-Systems Research, Riverside, v. 9, n. 2, p. 342-386, 2000.

QUINTERO, Pablo. Programas de desarrollo y comunidades indígenas en el Chaco central: capitalismo y colonialidad del poder en una formación social de fronteras. 2012. 312 f. Tesis (Doctorado en Antropología) - Facultad de Filosofía y Letras, Universidad de Buenos Aires, Buenos Aires, [2012].

SAID, Edward. Orientalismo. Madrid: Debate, 2002.

TAUSSIG, Michael. The devil and commodity fetishism in South America. Chapel Hill: University of North Carolina, 1980.

TERUEL, Ana. Misiones, economía y sociedad: la frontera chaqueña del noroeste argentino en el siglo XIX. Bernal: Universidad Nacional de Quilmes, 2005.

TRINCHERO, Héctor Hugo. Los dominios del demonio: civilización y barbarie en las fronteras de la nación. El Chaco central. Buenos Aires: EUDEBA, 2000.

Aromas de lo exótico (retornos del objeto): para una crítica del objeto antropológico y sus modos de reproducción. Buenos Aires: Editora SB, 2007.

WOLF, Eric. Pathways of power: building an anthropology of the modern world. Berkeley: University of California, 2001.

WRIGHT, Pablo. La colonización del espacio, la palabra y el cuerpo en el Chaco Argentino. Horizontes Antropológicos, Porto Alegre, v. 9, n. 19, p. 137-152, 2003. 
Recebido em: 06/04/2015* Aprovado em: 21/06/2015* Publicado em: 30/06/2015 